\title{
UPAYA PENCEGAHAN PENGARUH GADGET PADA ANAK MELALUI KEGIATAN PENYULUHAN DAN SOSIALISASI DAMPAK GADGET KEPADA IBU-IBU KELURAHAN TANJUNG UMA
}

\author{
EFFORTS TO PREVENT THE INFLUENCE OF GADGETS IN CHILDREN THROUGH \\ EVENTS AND SOCIALIZATION OF GADGET IMPACT TO THE MOTHERS OF TANJUNG \\ $U M A$
}

\author{
A. Yanizon ${ }^{1}$, Tamama Rofiqah ${ }^{2}$, Ramdani $^{3}$ \\ 123 (Prodi BK FKIP Universitas Riau Kepulauan,) \\ I'Konselor.nizon@gmail.com, ${ }^{2}$ Rofiqah87@gmail.com
}

\begin{abstract}
Abstrak
Pengabdian masyarakat ini bertujuan sebagaisalah satu upaya dalam meminimalisir pengaruh gadget dikalangan anak-anak dengan memberikan edukasi dampak penggunaan gadget kepada orang tua yaitu ibu.Hal ini disebabkan karena dewasa ini, peran ayah dan ibu dirumah sudah tidak proporsional lagi.Terkadang ibu harus ikut bekerja dan juga mengurus rumah, sehingga tidak optimal dalam merawat anak-anak.Gadget adalah salah satu solusi praktis agar anak bisa diam adalah anggapan yang salah yang masih ada sampai sekarang.Oleh karena itu, pentingnya edukasi terhadap ibu tentang dampak gadget ini harus terus di lakukan agar mampu mendampingi anak dalam tumbuh kembangnya.Berdasarkan survey di Kelurahan Tanjung Uma yang mayoritas masyarakat berprofesi sebagai nelayan, diperoleh data bahwa pengetahuan tentang perkembangan teknologi berupa gadget masih tergolong rendah.Sebagian membeli karena kebutuhan untuk menelepon dan terlihat canggih.Mereka belum mengerti seluk beluk gadget dan fitur-fitur aplikasi yang ada di dalamnya. Adapun hasil yang diperoleh dari kegiatan ini adalah peningkatan pemahaman ibu dalam memahami periodesasi tumbuh kembang anak, dampak positif dan negative dari gadget dan optimalisasi peran ibu di rumah diantaranya menghargai dan mendengarkan pendapat anak, kritis dan penuh selidik terhadap perilaku anak, memberi nasehat yang lengkap dan menyeluruh serta memberi peringatan keras jika melihat kesalahan pada anak.
\end{abstract}

Kata Kunci :Sosialisasi Pengaruh Gadget, Dampak Gadget terhadap anak

\begin{abstract}
This community service aims as an effort to minimize the influence of gadgets among children by providing education on the impact of using gadgets to parents, namely mothers. This is because today, the role of father and mother at home is no longer proportional. Sometimes mothers have to come to work and also take care of the house, so it is not optimal in caring for children. Gadgets are one practical solution so that children can be quiet is the wrong assumption that still exists today. Therefore, the importance of education to mothers about the impact of this gadget must continue to be done in order to be able to assist children in their growth and development. Based on a survey in Tanjung Uma Urban Village where the majority of people work as fishermen, data is obtained that knowledge about technological developments in the form of gadgets is still relatively low. Some buy because of the need to call and look sophisticated. They do not understand the ins and outs of gadgets and application features in it. As for the results obtained from this activity are increased understanding of the mother in understanding the growth and development period of the child, the positive and negative impacts of the gadget and optimizing the role of the mother at home including respecting and listening to the opinions of children, critical and full of inquiry towards the child's behavior, giving full and complete advice thorough and give a stern warning when seeing mistakes in children
\end{abstract}

Keywords: Socialization of the Effects of Gadgets, the Impact of Gadget on Children 


\section{PENDAHULUAN}

Kelurahan Tanjung uma, merupakan wilayah nelayan pertama dan tertua di kota Batam. Kelurahan yang berhadapan langsung dengan Singapura ini memiliki landscape khas masyarakat nelayan. Rumah-rumah kayu, alat-alat penangkap ikan yang terjejer disekitaran rumah beserta pompong(perahu tradisional) yang sedang merapat bisa kita temui disetiap sudut Tanjung Uma.Deretan rumah kayu tersebut, berjejer acak di atas birunya air laut.Masyarakat batam menyebut kampung-kampung nelayan tersebut dengan sebutan kampung tua.Sebagian besar masyarakat bermata pencaharian sebagai nelayan.Menghadapi perkembangan zaman yang semakin canggih dengan ditandai adanya teknologi berupa gadget, juga memberikan warna dan pengaruh pada masyarakat kelurahan Tanjung Uma.Salah satunya adalah komunikasi melalui gadget.Setiap rumah memiliki lebih dari satu gadget bahkan anak-anak juga sudah ada yang memiliki gadget sendiri.

Gadget adalah sebuah istilah dalam bahasa Inggris yang mengartikan sebuah alat elektronik kecil dengan berbagai macam fungsi menurut Osland Effendi(dalam Wahyu, 2016). Gadget sendiri dapat berupa komputer atau laptop, tablet PC, dan juga telepon seluler atau smartphone. Gadget pada era globalisasi sangatlah gampang dijumpai, sebab hampir semua kalangan masyarakat memiliki gadget.Realitanya, gadget tidak hanya beredar di kalangan remaja (usia 12-21 tahun) dan dewasa ataulanjut usia (usia 60 tahun keatas), tetapi juga beredar di kalangan anak-anak (usia 7-11 tahun) dan ironisnya lagi gadget bukan barang asing untuk anak (usia 3-6) tahun yang seharusnya belum layak menggunakan gadget.

Fenomena tersebut memang tidak lepas dari diberlakukannya pasar bebas dunia pada tahun 2008 yang dimana Indonesia termasuk dalam sasaran utama penjualan produk-produk elektronik khususnya teknologi gadget.Gadget yang awalnya hanya mampu dibeli oleh seseorang yang berpenghasilan tinggi, sekarang seseorang yang penghasilannya pas-pasan pun mampu membeli gadget dengan harga murah maupun dengan sistem pembayaran berkala.Selain itu pula, tak jarang sekarang banyak produsen-produsen gadget sengaja menjadikan anak-anak sebagai target pemasarannya.

Perilaku anak dalam menggunakan gadget memiliki dampak positif maupun negatif. Dampak positif dari penggunaan gadget antara lain untuk memudahkan seorang anak dalam mengasah kreativitas dan kecerdasan anak. Seperti adanya aplikasi mewarnai, belajar membaca, dan menulis huruf tentunya memberikan dampak positif bagi perkembangan otak 
anak.Anak-anak tidak memerlukan waktu dan tenaga yang lebih untuk belajar membaca dan menulis di buku atau kertas. Anak-anak juga akan lebih bersemangat untuk belajar karena aplikasi semacam ini biasanya dilengkapi oleh gambar-gambar yang menarik. Selain itu, kemampuan berimajinasi anak juga semakin terasah.

Berdasarkan hasil penelitian yang dilakukan oleh Tria dan Amy (2016), menyatakan bahwa gadget memiliki pengaruh yang positif terhadap personal sosial anak usia pra sekolah di TKIT Al Mukmin, hal ini disebabkan karena beberapa hal seperti yang diungkapkan beberapa orang tua wali murid antara lain:

1. Dari gadget anak dapat mengikuti pembelajaran seperti menghafal al qur'an, mengetahui kosakata bahasa inggris, dan lain-lain.

2. Anak merasa terbantu dalam membaca ataupun menghafal dari gadgetnya.

3. Gadget dapat dijadikan sebagai sarana hiburan bagi anak selagi dalam batasan waktu yang tidak berlebihan.

4. Anak dapat memahami perintah/bahasa asing yang ada dalam gadget dan membuatnya terbiasa.

5. Kecerdasan anak terasah saat ia dapat menyelesaikan suatu tahapan game yang lebih tinggi dari sebelumnya.

Salah satu yang nampak dari pengaruh positif gadget adalah anak lebih cepat dalam memahami kosa kata terutama dalam bahasa Inggris. Menurut Irfan \& Aghata (2018) permainan tradisional yang dimodifikasi juga dapat meningkatkan kemampuan kosa kata anak yaitu melalui permainan tradisional Slep Dur yang berasal dari Jawa Barat. Begitu juga dengan pengabdian masyarakat yang dilakukan oleh Erwin \& Sholehuddin (2018) dalam pengenalan materi dasar bahasa inggris bagi anak-anak usia dini di pulau mecan, pada pembelajarannya, tim menggunakan metode Group Discussion, artinya tim membagi peserta didik menjadi kelompok-kelompok kecil yang mana setiap kelompok dipandu oleh satu orang tutor. Selain itu, metode Demonstrasi dan Practice serta metode Contextual Teachingand Learning (CTL) adalah metode yang digunakan, artinya setiap peserta harus mengucapkan ulang apa yang diucapkan oleh tutor. Dalam proses pembelajaran materi Nouns ini, terlihat ada sekitar 10 orang peserta yang mencolok, artinya mereka angat berani dan dapat mengikuti pembelajaran dengan cepat, bahkan terkadang terjeadi rebutan mengacungkan tangan dalam menjawab pertanyaan dari tutor di menit-menit akhir pembelajara. Sedangkan terkait materi, para tutor menekankan pada kata benda yang mereka 
kenal secara konkrit atau sering mereka jumpai, sehingga memudahkan mereka untuk mengingatnya, apalagi tutor memberikan trik khusus dalam mengingat terjemahan kosakata yaitu dengan metoe persamaan huruf.

Namun demikian penggunaan gadget juga berdampak negatif yang cukup besar bagi anak.dengan adanya kemudahan dalam mengakses berbagai media infomasi dan teknologi, menyebabkan anak-anak menjadi malas bergerak dan beraktivitas. Mereka lebih memilih duduk diam di depan gadget dan menikmati dunia yang ada di dalam gadget tersebut. Mereka lambat laun telah melupakan kesenangan bermain dengan teman-teman seumuran mereka maupun dengan anggota-anggota keluarganya. Hal itu tentunya akan berdampak buruk terhadap kesehatan maupun perkembangan tumbuh anak. Selain itu, terlalu lama menghabiskan waktu di depan layar gadget membuat interaksi sosial anak juga mengalami gangguan. Sebagaimana disampaikan oleh Ismanto dan Onibala (2015) bahwa penggunaan gadget dikalangan anak-anak semakin memprihatinkan dan tentu memiliki dampak negatif terhadap tumbuh kembang. Terlihat jelas anak-anak lebih cepat beradaptasi dengan teknologi yang ada. Sehingga anak-anak sering terlena dengan kecanggihan gadget dengan fitur-fitur yang tersedia di dalamnya. Anak-anak yang sering menggunakan gadget, seringkali lupa dengan lingkungan sekitarnya. Mereka lebih memilih bermain menggunakan gadget dari pada bermain bersama dengan teman-teman dilingkungan sekitar tempat tinggalnya. Sehingga interaksi sosial antara anak dengan masyarakat, lingkungan sekitar berkurang, bahkan semakin luntur.

Sesuai dengan hasil seminar pada tanggal 25 September 2016 oleh Suwarsi (dalam Puji, 2017) ada beberapa perilaku anak terkait dengan gadget ini yang harus diwaspadai guru maupun orang tua yaitu:

1. Ketika keasyikan dengan gadget anak jadi kehilangan minat dalam kegiatan lain.

2. Anak tidak lagi suka bergaul atau bermain diluar rumah dengan teman sebaya.

3. Anak cenderung bersikap membela diri dan marah ketika ada upaya untuk mengurangi atau menghentikan penggunaan games.

4. Anak berani berbohong atau mencuri-curi waktu untuk bermain gadget.

Perilaku-perilaku tersebut merupakan tanda bahwa mereka sedang membutuhkan bantuan dalam menghentikan aktifitasnya dengan kecanduan bermain gadget.

Menurut para pakar pendidikan Sebaiknya seorang anak dikenalkan pada fungsi dan cara menggunakan gadget saat berusia enam tahun. Karena di usia tersebut perkembangan 
otak anak meningkat hingga 95\% dari otak orang dewasa. Sebab, jika mengenalkan gadget di bawah usia enam tahun, anak lebih banyak untuk bermainkarena anak tertarik dengan visual (gambar) dan suara yang beragam yang terdapat pada gadget (Maulida dalam Yusmi, 2015). Generasi penerus bangsa harus dididik lebih baik sejak dini karena pendidikan pada anak usia dini akan sangat berpengaruh besar pada kehidupan anak selanjutnya. Pengenalan budaya tradisional seperti permainan tradisional seringkali hanya didapatkan di sekolah saja, itu juga tidak terlalu luas dan mendalam.Kebanyakan hanya dikenalkan lewat gambar atau video, anak tidak secara langsung mengekspor dirinya dalam bermain (Widiawati \& Sugiman, dalam Yusmi, 2015).

Pendampingan dialogis dari orang tua sangat diperlukan untuk meminimalisir anak dari pengaruh negatif penggunaan gadget.Apabila anak sedang menggunakan gadget orang tua harus mendampingi anaknya, mengarahkan untuk membuka fitur-fitur yang sesuai dengan tahap perkembanganya. Pendampingan yang dimaksud adalah orang tua tidak hanya melihat anaknya yang sedang bermain gadget, akan tetapi orang tua harus mampu menjadi guru bagi anaknya. Gadget dijadikan media untuk menstimulasi anak.Misalnya, fitur-fitur yang sesuai dengan anak (Permainan) bisa dikembangkan untuk bahan diskusi supaya anak tidak terlalu fokus pada gadgetnya, dengan penerapan seperti itu anak dilatih untuk tetap berinteraksi dengan lingkungan sekitarnya.Apabila anak sudah terlanjur kecanduan gadget maka bisa dilakukan pembiasaan positif dan stimulasi yang tepat (Fadilah dalam Yusmi, 2015).Di fase ini semestinya anak banyak berinteraksi dengan orang lain agar dapat menstimulasi pancaindranya. Rasa ingin tahunya sangat besarMaka yang dia butuhkan adalah orang tua yang hangat dan penuh kasih sayang, dan saudara atau teman yang kooperatif. Di masa ini seyogyanya anak banyak bermain untuk mengembangkan gerak motoriknya(Yee Jin Shin, 2014)

Kegiatan pengabdian kepada masyarakat yang dilakukan oleh timDosen Program Studi BK Unrika adalah salah satu upaya dalam meminimalisir pengaruh gadget dikalangan anakanak dengan memberikan edukasi dampak penggunaan gadget kepada orang tua yaitu ibu. Karena peran sentral di rumah dipegang oleh Ibu.Pengoptimalan peran ibu dan ayah akan memberikan dampak positif terhadap perkembangan anak selanjutnya. Hal ini disebabkan karena dewasa ini, peran ayah dan ibu dirumah sudah tidak proporsional lagi.Terkadang ibu harus ikut bekerja dan juga mengurus rumah, sehingga tidak optimal dalam merawat anakanak.Gadget adalah salah satu solusi praktis agar anak bisa diam adalah anggapan yang salah 
yang masih ada sampai sekarang.Oleh karena itu, pentingnya edukasi terhadap ibu tentang dampak gadget ini harus terus di lakukan agar mampu mendampingi anak dalam tumbuh kembangnya.

\section{METODOLOGI}

Kegiatan "upaya pencegahan pengaruh gadget pada anak melalui kegiatan penyuluhan dan sosialisasi dampak gadgetkepada ibu-ibu"dilaksanakan pada Bulan Oktober 2019 di kelurahan Tanjung Uma Kecamatan Lubuk Baja Kota Batam.Bentuk kegiatan merupakan sosialisasi dan penyuluhan.Penyampaian materi sosialisasi dan penyuluhan dilakukan dengan ceramah dan Tanya jawab dengan warga.Materi yang disampaikan yaitu dampak gadget terhadap anak, periodesasi tumbuh kembang anak sesuai dengan perkembangan usianya, pendampingan orang tua terhadap anak dalam mengurangi pengaruh gadget dan pengoptimalam peran ibu sebagai pendidikan pertama bagi anak di rumah. Adapun permasalahan mitra dan solusi yang diberikan dapat dilihat pada bagan berikut :

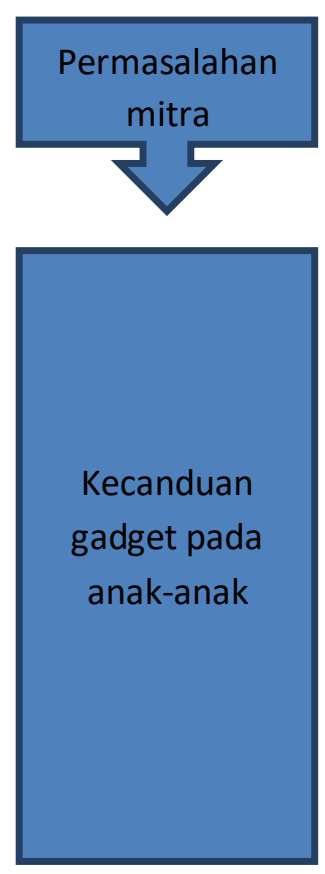

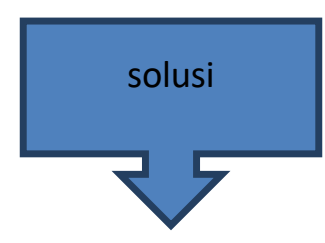

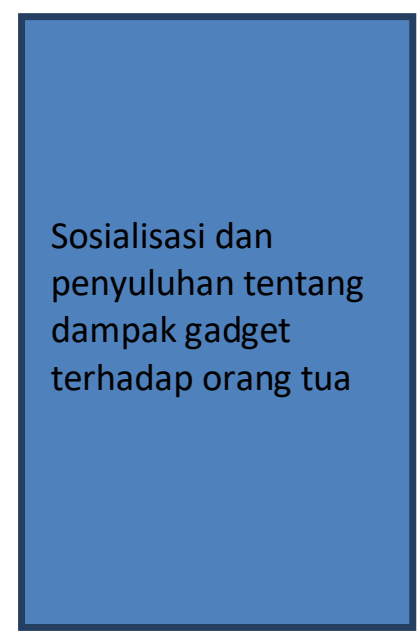

1. Peningkatan wawasan dan pengetahuan orang tua tentang gadget dan dampaknya

2. Pengoptimalan peran ibu dirumah sebagai pendamping anak dalam tumbuh kembangnya

3. Peningkatan pengetahuan ibu dalam periodesasi tumbuh kembang anak sesuai usia

Figur 1. Bagan permasalahan mitra

\section{HASIL DAN PEMBAHASAN}


Kegiatan pengabdian ini dilakukan dengan menggunakan metode ceramah. Tim memberikan materi melalui media visual dan dilanjutkan dengan tanya jawab antara peserta dan narasumber. Mengingat mayoritas masyarakat kelurahan Tanjung Uma berprofesi sebagai nelayan, ini berarti bahwa pengetahuan tentang perkembangan teknologi berupa gadget masih tergolong rendah.Sebagian membeli karena kebutuhan untuk menelepon dan terlihat canggih.Mereka belum mengerti seluk beluk gadget dan fitur-fitur aplikasi yang ada di dalamnya.Ada sebagian kecil yang memang sudah mengerti dan mampu menggunakan gadget dengan bijak. Adapun bentuk kegiatan pengabdian yang kami lakukan dapat diuraikan sebagai berikut :

\section{Berkenalan dan menyampaikan maksud dan tujuan kegiatan dilaksanakan}

Hal pertama yang kami lakukan adalah melakukan perkenalan untuk menciptakan rapport terhadap ibu-ibu yang telah hadir untuk mengikuti kegiatan sosialisasi ini. Perkenalan dilakukan dengan singkat, hangat dan terbuka agar apa yang disampaikan oleh kami bisa diterima dengan baik oleh peserta. Selanjutnya menyampaikan maksud dan tujuan dari pelaksanaan pengabdian ini, adalah agar para ibu memiliki wawasan dan pengetahuan mengenai dampak gadget terhadap anak baik dampak positif maupun dampak negatifnya, supaya anak mampu mengurangi kebiasaan bermain gadget, agar anak mampu mengikuti periodesasi perkembangan sesuai dengan usianya dan agar Ibu bisa memainkan peran yang optimal dalam mendampingi tumbuh kembang anaknya.

\section{Pemberian materi sosialisasi}

Setelah berkenalan, selanjutnya pemberian materi kepada peserta. Pemberian materi juga diselingi dengan Tanya jawab agar apa yang disampaikan dapat langsung dipahami oleh peserta. Semua peserta antusias mendengarkan dan bertanya.Pemberian materi ini juga dihadiri oleh anak-anak terutama yang sudah memasuki usia sekolah dasar dan menengah pertama.

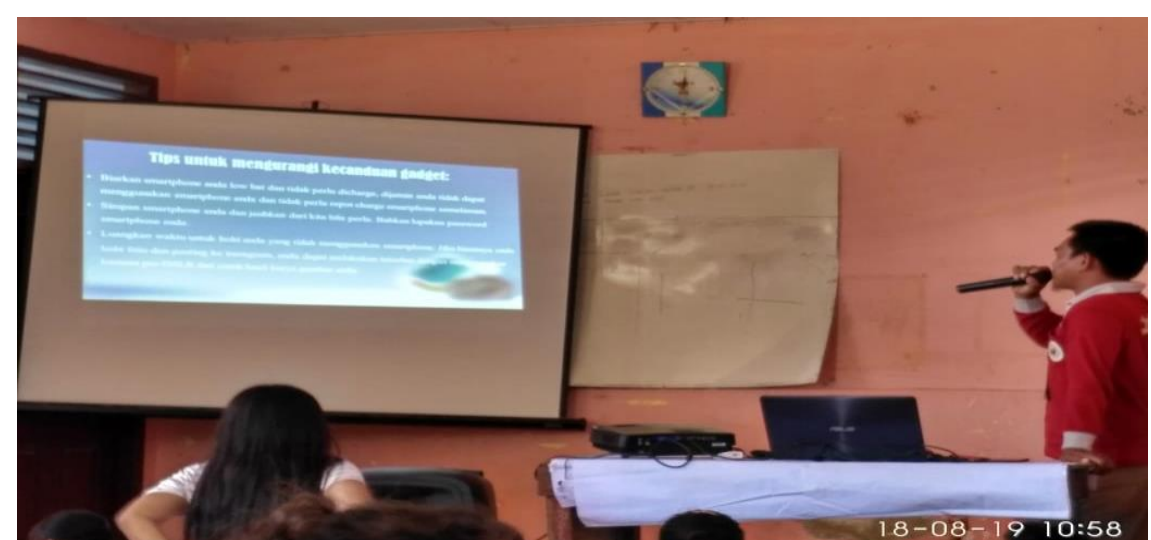


Figur 2. suasana pemberian materi tentang dampak gadget

Memasuki tahun 2000 ke atas, kecanggihan teknologi sudah mulai dirasakan oleh masyarakat.Keadaan ini tidak bisa dihindari karena sudah memasuki zamannya.Para orang tua harus memahami bagaimana kondisi anak yang hidup dan lahir di masa ini atau dikenal dengan istilah anak millennial.Anak-anak yang hidup di zaman millenial adalah mereka yang dikenal dengan generasi $\mathrm{Z}$ dan generasi alfa. Penelitian Bencsik, Csikos, dan Juhez (dalam Yanuar, 2016) menunjukkan masuknya Generasi Z didalam kelompok generasi, yang dapat dilihat dalam tabel berikut:

Tabel 1

Perbedaan Generasi

\begin{tabular}{cc}
\hline Tahun kelahiran & Nama Generasi \\
\hline $1925-1946$ & Veteran Generation \\
$1946-1960$ & Baby Boom generation \\
$1960-1980$ & X generation \\
$1980-1995$ & Y generation \\
$1995-2010$ & Z generation \\
$2010+$ & Alfa generation \\
\hline
\end{tabular}

Enam kelompok generasi tersebut memiliki karakteristik yang berbeda-beda.Generasi paling muda yang baru memasuki angkatan kerja adalah generasi $\mathrm{Z}$, disebut juga iGeneration atau generasi internet. Generasi $\mathrm{Z}$ memiliki kesamaan dengan generasi $\mathrm{Y}$, tapi generasi $\mathrm{Z}$ mampu mengaplikasikan semua kegiatan dalam satu waktu (multi tasking) seperti: menjalankan sosial media menggunakan ponsel, browsing menggunakan PC, dan mendengarkan musik menggunakan headset. Apapun yang dilakukan kebanyakan berhubungan dengan dunia maya.Sejak kecil generasi ini sudah mengenal teknologi dan akrab dengan gadget canggih yang secara tidak langsung berpengaruh terhadap kepribadian.Forbes Magazine membuat survei tentang generasi Z di Amerika Utara dan Selatan, di Afrika, di Eropa, di Asia dan di Timur Tengah.49 ribu anak-anak ditanya (Dill, dalam Yanuar, 2016).Atas dasar hasil itu dapat dikatakan bahwa generasi Z adalah generasi 
global pertama yang nyata.Teknologi tinggi dalam darah mereka, mereka telah tumbuh di lingkungan yang tidak pasti dan kompleks yang menentukan pandangan mereka tentang pekerjaan, belajar dan dunia.Mereka memiliki harapan yang berbeda di tempat kerja mereka, berorientasi karir, generasi profesional yang ambisius, memiliki kemampuan teknis-dan pengetahuan bahasa pada tingkat tinggi.Oleh karena itu, mereka tenagakerja yang sangat baik.Pengusaha harus mempersiapkan untuk terlibat generasi $\mathrm{Z}$ karena mereka adalah karyawan yang efektif di era digital.

Berdasarkan pemaparan di atas, dapat dipahami bahwa anak-anak yang lahir tahun 2000an sudah mengenal terknologi.Tak jarang terlihat fenomena anak-anak lebih paham dalam menggunakan gadget daripada orangtuanya.Sebagaimana yang terjadi di masyarakat kelurahan Tanjung Uma. Saat di tanyakan kepada ibu-ibu tentang fitur dan aplikasi dalam gadget, hanya sebagian yang mampu menjelaskan dan mengerti cara penggunaannya, termasuk dalam hal penggunaan media sosial seperti Whatshapp (WA), Facebook, Instagram, Tweeter. Sebagian besar hanya memahami fungsi smartphone untuk menelepon, mengirim pesan dan panggilan video.Selanjutnya memiliki akun media sosial juga sedikit, mereka bahkan tidak memiliki facebook, WA, instagram dan tweeter sedangkan anak mereka memiliki semua akun media sosial, terutama facebook dan instagram. Aplikasi-aplikasi dalam gadget yang booming seperti tik tok pun mereka punya.Apalagi dengan permainan online yang sedang marak. Para orang tua yang tidak mengerti berbagai macam game online akan tertinggal dengan anak mereka yang melek teknologi.

Penelitian yang dilakukan oleh Ridwan (2015) tentang perilaku kecanduan siswa terhadap aktifitas bermain game online, yang meliputi faktor-faktor penyebab kecanduan bermain game online, mekanisme psikologis perilaku kecanduan game online dan dampak sosial perilaku kecanduan bermain game online, menunjukkan hasil sebagai berikut :

1. Faktor-faktor penyebab kecanduan bermain game online pada subyek adalah:

a. Tersedianya fasilitas bermain game di rumah

b. Pengaruh lingkungan bermain game

c. Adanya keingintahuan tentang jenis game dan keinginan yang besar untuk memainkannya

2. Aspek ketergantungan yang dirasakan oleh siswa dipengaruhi oleh beberapa faktor adalah faktor internal yaitu mekanisme psikologis perilaku kecanduan bermain game online:

a. Bermain game online sebagai tempat mencari kesenangan 
b. Mendapatkan dunia baru dalam bermain game online

c. Berbagai luapan emosi dapat dirasakan sebagai suatu yang menarik dalam bermain game online

3. Dampak perilaku kecanduan bermain game online

a. Negatif (1.kedua subyek menjadi anak yang susah untuk di suruh oleh orang tua ketika asik bermain game 2. Jika sedang bermain kedua subyek menjadi lupa waktu 3.MT pernah bolos untuk pergi bermain game online.4. Kedua subyek menjadi kurang bergaul dengan teman-temannya dan lebih aktif dengan teman dunia maya dalam bermain game online)

b. Positif (1.kedua subyek mendapatkan pengetahuan tentang teknologi dan internet yang lebih baik. 2. kedua subyek paham dan dapat mengerti serta mengartikan bahasa inggris yangterdapat pada game online dan internet.)

\section{Evaluasi dan penutup kegiatan}

Setelah materi selesai dilakukan, selanjutnya memberikan evaluasi terhadap peningkatan wawasan dan pemahaman peserta, terutama para ibu yang memiliki anak yang aktivitasnya menggunakan gadget.Adapun evaluasi diberikan dengan meminta umpan balik dari para peserta berkaitan dengan materi yang telah disampaikan. Respon setiap peserta berbeda-beda, namun secara umum mereka merasakan manfaat setelah mendapatkan sosialisasi dan penyuluhan terhadap pengaruh gadget ini.Pengetahuan tentang gadget serta pengaruh dan dampaknya terhadap anak memberikan informasi penting terhadap orang tua.Kemudian terdapat beberapa hal yang bisa dilakukan oleh orang tua sebagai penanganan terhadap anak yang telah kecanduan bermain gadget, yaitu antara lain menurut Fera (2017) bahwa Al-Quran sebagai pedoman hidup sudah mencontohkan beragam model komunikasi interaktif antara orang tua dan anak yang memegang prinsip keseimbangan, tidak otoriter tidak pula permissive, antara lain :

1. Menghargai dan mendengarkan pendapat anak

2. Kritis dan penuh selidik terhadap perilaku anak

3. Memberi nasehat yang lengkap dan menyeluruh

4. Memberi peringatan keras jika melihat kesalahan pada anak 


\section{KESIMPULAN DAN SARAN}

Kesimpulan dari kegiatan ini adalah bahwa tidak semua orang tua mengikuti perkembangan dari sebuah tekhnologi terutama gadget, karena masih ditemukan orang tua yang tidak tau cara menggunakan gadget dan berbagai aplikasi di dalamnya, dimana kondisi ini berbanding terbalik dengan anak yang sudah paham dengan gadget. Disamping itu juga pengetahuan yang diperoleh orang tua setelah kegiatan ini dapat menjadi bekal dalam mengoptimalkan perannya dalam keluarga. Melihat fenomena gadget yang marak maka diperlukan upaya penyuluhan secara berkelanjutan agar orang tua mampu mendampingi anak nya dalam tumbuh kembang sesuai usia tanpa pengaruh gadget.

\section{REFERENSI}

Andriandi, F., D.M, (2017).Upaya Mengatasi Kecanduan Anak tergadap Gawai (Gadget) Melalui Model Komunikasi Interaktif Orang Tua dan Anak Berdasar AlQur'an.Proceedings Ancoms Kopertais Wilayah IV Surabaya. Vol. 2 (2); 645-653

Ashari, E. \& Shalehoddin, (2018).Pengenalan Materi Dasar Bahasa Inggris Bagi Anak-Anak Usia Dini Di Pulau Mecan, Sekanak Raya, Belakang Padang, Batam. Minda Baharu, Vol, $2(1) ; 1-9$

Chusna, P. A.(2017). Pengaruh Media Gadget Pada Perkembangan Karakter Anak, Dinamika Penelitian, Media Komunikasi Sosial Keagamaan, Vol, 17 (2); 315-329.

Irfan \& Aghata (2018).Peningkatan kosakata bahasa inggris Melalui permainan tradisional yang dimodifikasi.Jurnal Lensa Pendas, Vol, 3 (2);1-7.

Putra, Y.S (2016). Theoritical Review : Teori Perbedaan Generasi. Among Makarti, Vol 9 (18); 123-134.

Syahran, R (2015). Ketergantungan Game Online dan Penanganannya.Jurnal Psikologi Pendidikan \& Konseling. Vol, 1 (1); 84-92.

Tria \& Amy (2016) Pengaruh Penggunaan Gadget Terhadap Personal Sosial Anak Usia Pra Sekolah Di Tkit Al Mukmin, Profesi. Vol 13 (2); 72-78.

Wahyu \&Nurul (2016) Dampak Penggunaan Gadget Terhadap Interksi Sosial Anak Usia 56 Tahun. Jurnal PAUD Teratai. Vol 5 (3); 182-186.

Warusyah, Y (2015). Pentingnya "Pendampingan Dialogis" Orang Tua Dalam Penggunaan Gadget Pada Anak Usia Dini, Prosiding Seminar Nasional Pendidikan "Inovasi Pembelajaran untuk Pendidikan Berkemajuan" FKIP Universitas Muhammadiyah Ponorogo ; 130-138 
Yee-Jin, S (2014) Mendidik Anak di Era Digital. Terj. Adji Annisa, Jakarta: Noura Books.

Yudi, I \& Onibala, F (2015). Hubungan Penggunaan Gadget Dengan Tingkat Prestasi Siswa Di Sma Negeri 9 Manad. Ejoural Keperawatan Vol 3 (2): 1-6. 